\title{
Evaluation of effect of silymarin on granulosa cell apoptosis and follicular development in patients undergoing in vitro fertilization
}

\author{
N. Moosavifar, ${ }^{7}$ A.H. Mohammadpour, ${ }^{2,3}$ M. Jallali, ${ }^{1}$ G. Karimi ${ }^{2,4}$ and H. Saberi ${ }^{2}$
}

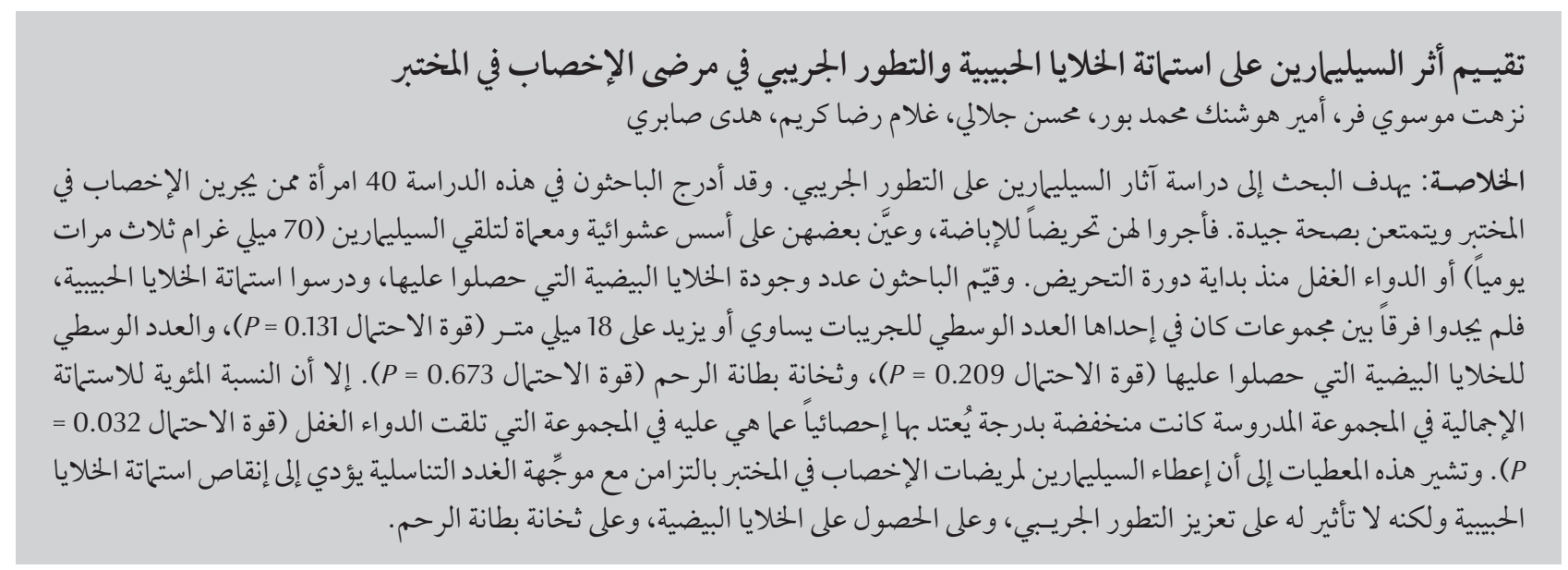

ABSTRACT To investigate the effects of silymarin on follicular development, we enrolled 40 healthy women undergoing in vitro fertilization (IVF) due to male factor infertility in this trial. They underwent ovulation induction and on a random and blind basis, patients were assigned to receive silymarin $(70 \mathrm{mg} \times 3$ /day) or placebo from the beginning of the induction cycle. The number and quality of oocytes retrieved were evaluated and apoptosis of granolusa cells was studied. There was no significant difference between the groups for mean number of follicles $\geq 18 \mathrm{~mm}(P=0.131)$, mean number of oocytes retrieved $(P=0.209)$ or endometrial thickness $(P=0.673)$. However, the proportion of total apoptosis in the study group was significantly lower than in the placebo group $(P=0.032)$. These data suggest that administration of silymarin in IVF patients concomitantly with gonadotropin results in reduction of granolusa cell apoptosis but does not have any effect in promotion of follicular development, oocyte retrieval or endometrial thickness.

Évaluation de l'effet de la silymarine sur l'apoptose des cellules de la granulosa et le développement folliculaire chez les patientes subissant une fécondation in vitro

RÉSUMÉ Pour étudier les effets de la silymarine sur le développement folliculaire, nous avons recruté 40 femmes en bonne santé subissant une fécondation in vitro (FIV) en raison d'une infertilité masculine. Ces patientes ont été soumises à une induction d'ovulation et ont reçu, sur la base d'une répartition aléatoire et en aveugle, de la silymarine (70 mg × 3 fois par jour) ou un placebo, dès le début du cycle d'induction. Le nombre et la qualité des ovocytes prélevés ont été évalués, et l'apoptose des cellules de la granulosa a été étudiée. Aucune différence significative n'a été observée entre les deux groupes en termes de nombre moyen de follicules $\geq$ $18 \mathrm{~mm}(P=0,131)$, de nombre moyen d'ovocytes prélevés $(P=0,209)$ ou d'épaisseur de l'endomètre $(P=0,673)$. Toutefois, la proportion de l'apoptose totale dans le groupe d'expérimentation était significativement inférieure à celle observée dans le groupe sous placebo $(P=0,032)$. Ces données suggèrent que, chez les patientes qui subissent une FIV, I'administration concomitante de silymarine et de gonadotrophine induit une réduction de l'apoptose des cellules de la granulosa, mais n'a aucun effet sur la stimulation du développement folliculaire, sur le nombre d'ovocytes prélevés ni sur l'épaisseur de l'endomètre.

${ }^{7}$ Women's Health Research Centre; ${ }^{2}$ Pharmaceutical Research Centre; ${ }^{3}$ School of Pharmacy; ${ }^{4}$ Medical Toxicology Resarch Centre, Mashhad University of Medical Sciences, Mashhad, Islamic Republic of Iran (Correspondence to A.H. Mohammadpour: mohamadpoorah@mums.ac.ir). Received 09/04/08; accepted: 13/04/08 


\section{Introduction}

Normal maturation and growth of oocytes depends on adequate support from ovarian granolusa cells of the follicles [1]. Therefore, apoptosis of granolusa cells seems to have a negative effect on follicular development, oocyte quality and pregnancy rates [2].

Reactive oxygen species (ROS) serve not only as key signal molecules in physiological processes, but also have a role in pathological processes in female reproduction. ROS are involved in the modulation of an entire spectrum of physiological reproductive functions such as folliculogenesis, oocyte maturation, steroidogenesis, corpus luteal function and luteolysis [3]. The role of ROS in gynaecological disease and assisted reproduction has been widely studied in recent years.

Follicular fluid microenvironment has a crucial role in determining the quality of the oocyte. There is a potent antioxidant enzymatic defence in human follicular fluid that protects oocytes against oxidative stress (OS) $[3,4]$. Changes in the antioxidant enzymatic pattern could impair ROS scavenging efficacy in the follicular environment and result in OS. It has been shown that increased ROS concentration in the follicular fluid has been associated with increased granolusa cell apoptosis and thus impaired follicular development [5].

Silymarin, which is a standardized extract (a mixture of 3 isomeric flavonolignans) from dried fruits of milk thistle, Silybum marianum, appears to function as an antioxidant by scavenging free radicals to increase glutathione levels and activate superoxide dismutase (SOD) and glutathione peroxides; it also inhibits the formation of damaging chemicals[6,7]. It has also been shown to act as a membrane stabilizer, preventing lipoperoxidation and associated cell damage in some experimental models [8].
In a study by Plíšková et al. silymarin and its components elicited partial or full estrogen receptor activation. Silybin B, one of the components of silymarin, has (probable) weak estrogen receptor (ER)-mediated activity. Silybin-A and other flavonolignans are inactive, and taxifolin, which is a minor constituent of silymarin, is a potent ER-agonist [9]. Considering the antioxidant effect and estrogen receptor activity, it is suggested that silymarin and its components can affect folliculogenesis, oocyte maturation, granulosa cell apoptosis and endometrial thickness.

This is the first attempt to evaluate the effects of silymarin on folliculogenesis and granolusa cell apoptosis. To study the actual effect of silymarin and to determine whether supplementation can increase the pregnancy rate in infertile patients undergoing assisted reproduction, we carried out an interventional study.

\section{Methods}

Forty healthy women undergoing in vitro fertilization (IVF) for male factor infertility were included from the patients attending the Infertility Clinic of Monasteries Hospital at Mashhad University of Medical Sciences between April 2006 and April 2007. Inclusion criteria were: the cause of infertility should be exclusively a male factor (total motile sperm count $<5$ million per sample); women should undergo intracytoplasmic sperm injection cycles; age should be 18-35 years. Exclusion criteria were: cigarette smoking and taking vitamin C, vitamin E and other antioxidants recently or concurrently.

For all patients, demographic data, physical examination findings, hormonal and tubal assessment and probable concomitant disease were recorded.

Before the beginning of the cycles, patients were divided into 2 groups of 20 on a random and blinded basis. All the patients underwent a standard long protocol of IVF cycle. After pituitary down regulation with $\mathrm{GnRh}$ analogue and from the first day of ovarian stimulation, one group of patients received gonadotropin plus silymarin $(70 \mathrm{mg} \times 3$ / day) and the other group gonadotropin plus placebo. Transvaginal ultrasound examination was performed to evaluate follicular development and endometrial thickness on the sixth day after human menopausal gonadotropin administration and then every other day according to the follicular size. When at least 3 follicles measured $\geq 18 \mathrm{~mm}$, human chorionic gonadotropin (HCG) $10000 \mathrm{U}$ was administered intramuscularly. 34-36 h after HCG injection, egg recovery was performed under transvaginal ultrasonographic guidance.

The number of follicles and endometrial thickness were recorded and oocyte quality examined by an embryologist according to a comprehensive grading system, which included evaluation of oocyte maturational status, morphological quality, and fertilization capacity from grade I to grade IV [10].

Measurement of granulosa cell apoptosis was performed by flow cytometry. Apoptotic granolusa cells were detected using Annexin V and propidium iodide. For 10 women selected at random (due to economic constraints, we could not manage more) granulosa cells were isolated from each aspirated follicle using hyaluronidase. Analysis of phosphatidylserine exposure in granolusa cells was carried out by the following process: first granolusa cells were washed with calcium buffer and the cell concentration was adjusted to 1.5 $\times 10^{6}$ cells $/ \mathrm{mL}$ in calcium buffer. Then $10 \mu \mathrm{L}$ annexin V-FITC was added to $100 \mu \mathrm{L}$ cell suspension and incubated for 20 minutes on ice in the dark. After incubation, the cells were washed again with calcium buffer; $10 \mu \mathrm{L}$ propidium iodide was added to the suspension and incubated at least 10 minutes on ice, then the cell suspension was ready to analyse by flow cytometer. Positive con- 
trol was carried out by Dexamethasone incubation

The number of follicles of different sizes, endometrial thickness on day of HCG injection, the number, and quality of oocytes retrieved and the percentage of early and total apoptosis were analysed for the 2 groups. $P$-value $<0.05$ was considered significant.

\section{Results}

All 40 women completed the study. The mean age of patients was 28.38 [standard deviation (SD) 4.59] years in the study group and 27.59 (SD 4.05) years in the placebo group, and was not significantly different. Other paraclinical parameters are listed in Table 1.

The mean number of follicles $\geq 18 \mathrm{~mm}$ and $15-18 \mathrm{~mm}$ and also the total number of oocytes retrieved were not significantly greater in the therapeutic group $(P=0.118,0.360$ and 0.125 respectively) (Table 2 ). There was no significant difference between the 2 groups regarding endometrial thickness $(P=0.673)$.

The proportion of early apoptosis and total apoptosis in therapeutic group was significantly lower than in the control group ( $P=0.014$ and 0.027 respectively) while late apoptosis was reduced, but not significantly $(P=0.086)$ (Table 3).

\section{Discussion}

Granulosa cells are essential in the normal follicular maturation process since they produce steroidal hormones and growth factors and also they play a crucial role in follicular atresia. Apoptosis of granolusa cells seems to have a negative effect on follicular maturation. A higher incidence of apoptotic granulosa cell has been associated with fewer oocytes retrieved and poorer quality of oocytes and embryos [2].

\begin{tabular}{lccc}
\hline \multicolumn{4}{l}{ Table 1 Baseline characteristics of the sylimarin group and the placebo group } \\
\hline Parameter & Therapeutic group & Control group & Overall \\
& Mean (SD) & Mean (SD) & Mean (SD) \\
Age (years) & $28.38(4.59)$ & $27.59(4.05)$ & $27.97(4.29)$ \\
$\mathrm{LH}(\mathrm{mlU} / \mathrm{mL})$ on day 3 & $5.75(3.20)$ & $5.17(2.20)$ & $5.45(2.72)$ \\
$\mathrm{FSH}(\mathrm{mlU} / \mathrm{mL})$ on day 3 & $6.68(2.16)$ & $6.89(3.10)$ & $6.79(2.65)$ \\
$\mathrm{LH} / \mathrm{FSH}$ on day 3 & $0.94(0.58)$ & $0.91(0.54)$ & $0.92(0.55)$ \\
$\mathrm{TSH}(\mathrm{mlU} / \mathrm{mL})$ & $1.84(1.33)$ & $2.09(1.30)$ & $1.97(1.30)$ \\
Prolactin $(\mathrm{mlU} / \mathrm{mL})$ & $218.71(218.23)$ & $237.22(230.38)$ & $228.18(222.04)$ \\
\hline
\end{tabular}

\section{$S D=$ standard deviation.}

$\mathrm{LH}=$ luteinizing hormone.

FSH = follicle stimulating hormone.

TSH $=$ thyroid stimulating hormone.
Various pathological stimuli such as OS can initiate apoptosis in mammalian oocytes [11]. Intra-cellular accumulation of ROS, i.e. OS, can damage cells by causing nucleic acid strand breaks, lipid peroxidation, protein degradation and ultimately, cell death [12]. It has been suggested that steroidogenically active cells such as granulosa cells of antral follicles, require high levels of energy production and thus generate large amounts of ROS [13]. Therefore it is possible that $\mathrm{OS}$ is involved in the mechanisms that trigger apoptosis in healthy steroidogenic antral follicles [2].

An increasing number of published studies have pointed towards increased importance of the role of OS in female come by reducing generation of ROS or increasing the amounts of total antioxidant capacity.

Pradeep et al. indicated that silymarin exhibits good hepatoprotectivity and antioxidant potential against diethyl nitrosamine-induced hepatocellular damage in rats [14]. reproduction [2,3]. OS can be over-

Table 2 Mean number of follicles and oocytes retrieved in the sylimarin group and the placebo group

\begin{tabular}{lccc}
\hline Parameter & $\begin{array}{c}\text { Therapeutic } \\
\text { group } \\
\text { Mean (SD) }\end{array}$ & $\begin{array}{c}\text { Control group } \\
\text { Mean (SD) }\end{array}$ & P-value $^{\text {a }}$ \\
No. of follicles $\geq 18 \mathrm{~mm}$ & $7.76(3.37)$ & $6.14(3.40)$ & 0.118 \\
No. of follicles 15-17 mm & $3.28(3.27)$ & $4.61(4.35)$ & 0.360 \\
No. of oocytes retrieved & $10.09(3.56)$ & $8.52(4.54)$ & 0.125 \\
Endometrial thickness $(\mathrm{mm})$ & $9.83(1.79)$ & $10.08(2.11)$ & 0.673 \\
\hline
\end{tabular}

$S D=$ standard deviation.

${ }^{a}$ Mann-Whitney $U$-test.

Table 3 Mean percentage of granulosa cell apoptosis in the sylimarin group and the placebo group

\begin{tabular}{lccc}
\hline Apoptosis & $\begin{array}{c}\text { Therapeutic } \\
\text { group } \\
\text { Mean (SD) }\end{array}$ & Control group & Pe-value \\
Early & $2.70(1.61)$ & $13.77(10.06)$ & 0.014 \\
Late & $2.17(2.65)$ & $5.77(2.33)$ & 0.086 \\
Total & $4.88(2.48)$ & $19.54(12.15)$ & 0.027 \\
\hline
\end{tabular}

$S D=$ standard deviation.

${ }^{a}$ Mann-Whitney U-test. 
Regarding the antioxidant effect of silymarin on fertility, Jancar et al. reported that an increased percentage of ROS-producing granulosa cells resulted in fewer oocytes retrieved and diminished implantation rate [2].

Tsani et al. evaluated opposing effects of glutathione depletion and follicle-stimulating hormone on reactive oxygen species and apoptosis in cultured pre-ovulatory follicles. They found that OS induced apoptosis in pre-ovulatory follicles and antiapoptotic effect of follicle stimulating hormone was mediated by stimulation of follicular glutathione synthesis and suppression of ROS production [15]. Our findings demonstrated that apoptosis of granulosa cells was reduced but follicular development was not increased significantly by silymarin administration in women undergoing intracytoplasmic sperm injection for male factor infertility.

In a study by Plíšková et al. silymarin elicited partial ER activation, with the silybin B component being probably responsible for a majority of the weak ER-mediated activity of silymarin [9]; silybin A and other flavonolignans were found to be inactive, and the potent ER-agonist toxifolin is only a minor constituent of silymarin. In the study by Kummer et al. uterotrophic effects of 30 days treatment with Silymarin were evident from increased heights of the luminal epithelium and endometrium of ovariectomized rats [16].

In our study the endometrial thickness on the day of HCG injection did not differ significantly in the treatment and control groups; this may be because of the short treatment period.

\section{References}

1. Sharpe-Timms KL, Zimmer RL. Oocyte and pre-embryo classification. In: Keel BA, May JV, De Jonge CJ, eds. Handbook of the assisted reproduction laboratory. Lodon, CRC Press LLC, 2000:179-96.

2. Jancar $\mathrm{N}$ et al. Effect of opoptosis and reactive oxygen species production in human granolusa cells on oocyte fertilization and blastocyst development. Journal of assisted reproduction and genetics, 2007, 24:91-7.

3. Agarwal A, Gupta S, Sharma RK. Role of oxidative stress in female reproduction. Reproductive biology and endocrinology, 2005, 14:3-28.

4. Carbone MC et al. Antioxidant enzymatic defences in human follicular fluid: characterization and age-dependent changes. Molecular human reproduction, 2003, 9(11):639-43.

5. Valdez KE, Cuneo SP, Turzillo AM. Regulation of apoptosis in the atresia of dominant bovine follicles of the first follicular wave following ovulation. Journal of reproduction, 2005, 130:71-81.

6. Dermarderosian A. The review of natural products, 1st ed. St Louis, Facts and Comparisons Inc., 2001:405-9.

7. Fleming T, ed. PDR for herbal medicines. Montvale, New Jersey, Medical Economics Co., 2005:566-7.

8. Shalan MG et al. Amelioration of lead toxicity on rat liver with vitamin C and silymarin supplements. Toxicology, 2006, 206:1-15.
9. Plíšková $\mathrm{M}$ et al. Effects of silymarin flavonolignans and synthetic silybin derivatives on estrogen and aryl hydrocarbon receptor activation. Toxicology, 2005, 215(1/2):80-9.

10. Dale B, Di Matteo L, Wilding M. Mitochondria in reproduction. In: Elder K, Cohen J, eds. Human preimplantation embryo selection. London, Informa HealthCare, 2007:276-9.

11. Roth Z, Hansen PJ. Involvment of apoptosis in distruption of developmental competence of bovine oocytes by heat shock during maturation. Biology of reproduction, 2004, 71(6):1898906.

12. Yu BP. Cellular defences against damage from reactive oxygen species. Physiological reviews, 1994, 74:139-62.

13. Rapoport R, Shlan D, Hanukoglu I. Electron leakage from the adrenal cortex mito chondrial P450 scc and P450 cll systems: $\mathrm{NADPH}$ and steroid dependence. Archives of biochemistry and biophysics, 199, 5617:412-6.

14. Pradeep K, Mohan CV, Karthikeyan S. Silymarin modulates the oxidant - antioxidant imbalance during diethyl nitrosamine induced oxidative stress in rats. European journal of pharmacology, 2007, 560:110-6.

15. Tsai-Turton M, Luderer U. Opposing effects of glutathione depletion and follicle-simulating hormone on reactive oxygen species and apoptosis in cultured preovlatory rat follicles. Endocrinology, 2006, 147(3):1224-36.

16. Kummer $\mathrm{V}$ et al. Estrogenic effects of silymarin in ovariectomized rats. Veterinarni-Medicina-UZPI (Czech Republic), 2001, 46:17-23. 